\title{
Proximate Composition of Peanut Milk Prepared by Different Methods
}

\author{
Perugu Balachandra Yadav $^{1 *}$, L. Edukondalu ${ }^{2}$, S. Patel $^{1}$ and D. Bhaskara Rao ${ }^{3}$ \\ ${ }^{1}$ ICAR-Indian Agricultural Research Institute, New Delhi, India \\ ${ }^{2}$ Department of Agricultural Processing and Food Engineering, College of Agricultural \\ Engineering, Bapatla, Andhra Pradesh, India \\ ${ }^{3}$ Acharya N.G. Ranga Agricultural University, Guntur, Andhra Pradesh, India. \\ *Corresponding author
}

\begin{tabular}{|c|}
\hline Keywords \\
\hline $\begin{array}{l}\text { Peanut milk, } \\
\text { Soaking, Roasting }\end{array}$ \\
\hline Article Info \\
\hline $\begin{array}{l}\text { Accepted: } \\
18 \text { September } 2018 \\
\text { Available Online: } \\
10 \text { October } 2018\end{array}$ \\
\hline
\end{tabular}

\section{A B S T R A C T}

Peanuts (Arachis hypogaea) are good food for infants suffering from various forms of malnutrition and for individual with lactose intolerance allergies. Peanut milk does not contain any lactose and is therefore suitable for people with lactose intolerance. In this study, peanut milk was prepared by three different methods namely, by normal soaking, soaking in $1 \% \mathrm{NaHCO}_{3}$ and roasting. The proximate composition of peanut milk consists of moisture content, protein content, carbohydrate content, fat content, ash content, total solids and $\mathrm{pH}$ values. Quality of the milk prepared by these three different methods was compared. The moisture in raw peanuts was $5.25 \%(\mathrm{wb})$. The raw peanuts recorded a good amount of protein $(25.48 \%)$ which is good for health. The carbohydrates which consists mainly sugars were also present which occupied the share of nutritive value up to $17.43 \%$. The fat and ash contents in the peanuts were found to be 47.27 and $1.84 \%$ respectively. In normal soaking method of peanut milk preparation the values of proteins, carbohydrates, fat and ash were $3.68 \%, 4.70 \%, 2.16 \%$ and $0.24 \%$ respectively. In soaking in $1 \% \mathrm{NaHCO}_{3}$ method of peanut milk preparation, the values were $3.11 \%, 5.58 \%, 1.86 \%$ and $0.26 \%$ respectively. In roasting method of peanut milk preparation the values were $3.23 \%, 3.78 \%$, $3.53 \%$ and $0.18 \%$ respectively.

\section{Introduction}

Peanuts (Arachis hypogaea) originated in South America where the crop existed for thousands of years. Peanuts played an important role in the diet of the Aztecs and other native Indians in South America and Mexico.

India is one of the largest producers of oilseeds in the world and occupies an important position in the Indian agricultural economy. It is estimated that nine oilseeds namely groundnut, rapeseed-mustard, soybean, sunflower, safflower, sesame, niger, castor and linseed, accounted for an area of 23.44 million hectares with the production of 25.14 million tons (Madhusudhana, 2013). Groundnut is called as the 'King' of oilseeds. Groundnut is also called as wonder nut and poor men's cashew nut. Groundnut is one of the most important cash crops of our country. Peanuts have been used as a major source of edible oil and protein meal and considered highly valuable for human and animal nutrition in developing countries (Fekria et al., 
2012). Peanuts are rich source of multiple nutrients and their consumption is associated with various health benefits, including reduced cardiovascular disease risk (Mattes et al., 2008). Peanuts have been developed into a food for infants suffering from various forms of malnutrition and for individual with lactose intolerance allergies (Considine and Considine, 1997).

Peanut milk is a non-dairy beverage created using peanuts and water. Recipe variations include salt, sweeteners, and grains. It does not contain any lactose and is therefore suitable for people with lactose intolerance. Similar in production to almond milk, soy milk, and rice milk, the peanuts are typically ground, soaked, sometimes heated, and then filtered through a fine filter: the resulting liquid is considered the "milk".

\section{Materials and Methods}

All the research work has been done in the laboratory of College of Agricultural Engineering, Bapatla, Guntur, and PostHarvest Technology Centre, Bapatla, (Andhra Pradesh).

\section{Preparation of peanut milk}

Peanut milk was prepared using three different methods as follows:-

\section{Normal soaking}

Peanut milk was prepared by a method reported by Jain (2013) with slight modifications. $100 \mathrm{~g}$ of peanuts were soaked in water in a ratio of 1:3 (kernel: water) for 18 hours and they were be dehusked. The dehusked kernels were washed with water and ground with hot water in a ratio of 1:6 (kernels to water) in the grinder. The slurry formed was sieved by muslin cloth and peanut milk was produced (Fig. 1).

\section{Soaking in $1 \% \mathrm{NaHCO}_{3}$}

As per the method of Saio (1986) with slight modification. $100 \mathrm{~g}$ of peanuts were soaked for $18 \mathrm{~h}$ in $1 \% \mathrm{NaHCO}_{3}$ (1:3 ratio kernels to $1 \%$ $\mathrm{NaHCO}_{3}$ ). After soaking, peanuts were dehusked. The dehusked kernels were washed with water and ground with hot water in a ratio of 1:6 (kernels to water) in the grinder. The slurry formed was sieved by muslin cloth and peanut milk was produced. $\mathrm{NaHCO}_{3}$ was used to the removal of beany flavour in the final product, and to help soften the peanuts.

\section{Roasting}

Peanut milk was prepared by a method reported by Salunkhe and Kadam (1989) with slight modifications. Sorted peanut seeds were roasted at $130^{\circ} \mathrm{C}$ for $20 \mathrm{~min}$ in an oven. The seeds were de-skinned and weighed before being soaked in $1 \% \mathrm{NaHCO}_{3}$ for at least $14 \mathrm{~h}$. The de-skinned peanut kernels were washed with clean water. The kernels were mixed with water in a ratio of 1:6 [peanuts $(\mathrm{g})$ : water $(\mathrm{ml})$ ] and transferred to a blender where they were blended for 5 min. The slurry formed was sieved by muslin cloth and peanut milk was produced.

\section{Proximate composition}

Moisture, Ash, Fat, Protein, Crude fibre, Carbohydrate and Total solids was analyzed by following the AOAC (2000) methods.

\section{Results and Discussion}

\section{Proximate Analysis of peanut milk based on different methods of preparation}

The proximate analysis of peanut milk was carried out in the laboratory of College of Agricultural Engineering, Bapatla. The proximate composition of peanut milk consists of moisture content, protein content, 
carbohydrate content, fat content, ash content, total solids and $\mathrm{pH}$ values. Various treatments for peanuts were given before peanut milk preparation and the physic-chemical characteristics of milk were determined.

\section{Proximate analysis of raw peanuts}

The proximate analysis of peanuts was conducted for the comparative study of its nutritive value with the peanut milk prepared in different methods. The raw peanuts recorded a good amount of protein (25.48\%) which is good for health. The carbohydrates which consist mainly sugars were also present which occupied the share of nutritive value up to $17.43 \%$. The moisture in raw peanuts was $5.25 \%$. The fat content in the peanuts was found to be $47.27 \%$. The ash content present in the peanuts was $1.84 \%$.

\section{Proximate analysis of peanut milk prepared by normal soaking}

In this method, peanuts were soaked in water for 18 hours and the milk was prepared. The moisture content of peanut milk prepared by normal soaking method was $89.20 \%$ (wb) whereas, the moisture content of raw peanuts was $5.25 \%$ (wb). The high moisture content in the milk compared to raw peanuts was due to soaking and addition of water during the milk preparation. The values of proteins, carbohydrates, fat and ash in peanut milk were $3.68 \%, 4.70 \%, 2.16 \%$ and $0.24 \%$ respectively.

The corresponding values for raw peanut were $25.48 \%, \quad 17.43 \%, \quad 47.27 \%$ and $1.84 \%$ respectively. It was observed that all the quality parameters of milk were less compared to the raw peanuts.

Fig.1 Prepared peanut milk

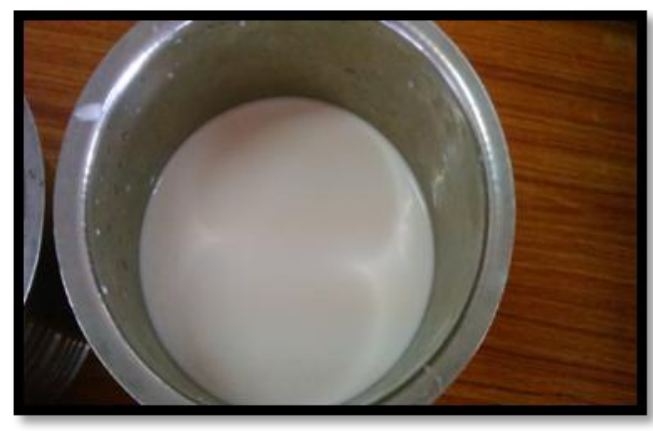

Proximate analysis of peanut milk prepared by soaking in $1 \%$ sodium bicarbonate

In this method, peanuts were soaked in a solution consisting $1 \%$ sodium bicarbonate in $100 \%$ water for 18 hours and then the milk was prepared. The moisture content of peanut milk prepared in this method was $89.06 \%$ (wb) whereas, the moisture content of raw peanuts was $5.25 \%(\mathrm{wb})$. The high moisture content in the milk compared to raw peanuts was due to soaking and addition of water during the milk preparation. The values of

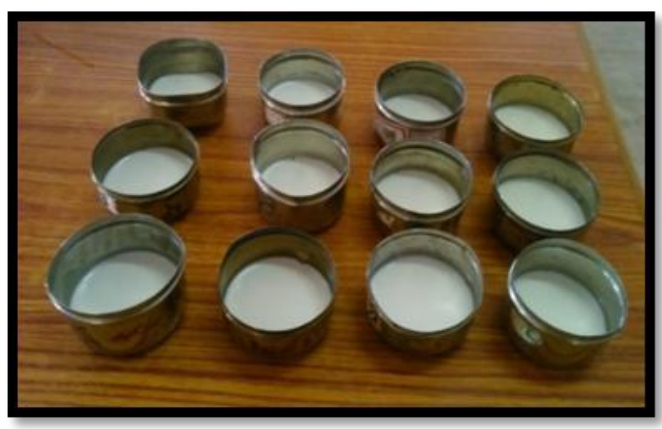

proteins, carbohydrates, fat and ash in peanut milk were $3.11 \%, 5.58 \%, 1.86 \%$ and $0.26 \%$ respectively. The corresponding values for raw peanut were $25.48 \%, 17.43 \%, 47.27 \%$ and $1.84 \%$ respectively. It was observed that all the quality parameters of milk were less compared to the raw peanuts.

\section{Proximate analysis of peanut milk prepared by roasting}

In this treatment peanuts were roasted in a micro oven for $20 \mathrm{~min}$ and soaked in water for 14 hours. The moisture content of peanut 
milk prepared in this method was $89.26 \%$ (wb) whereas, the moisture content of raw peanuts was $5.25 \%(\mathrm{wb})$. The high moisture content in the milk compared to raw peanuts was due to soaking and addition of water during the milk preparation. The values of proteins, carbohydrates, fat and ash in peanut milk were $3.23 \%, 3.78 \%, 3.53 \%$ and $0.18 \%$ respectively. The corresponding values for raw peanut were $25.48 \%, 17.43 \%, 47.27 \%$ and $1.84 \%$ respectively. It was observed that all the quality parameters of milk were less compared to the raw peanuts.

Based on the observations it was concluded that the roasting of peanut had a significant effect in improving the quality of the peanut milk on the basis of proximate analysis. It also reduces the time of soaking i.e. $14 \mathrm{~h}$ as compared to $18 \mathrm{~h}$ in other methods.

\section{References}

AOAC (2000) Methods of analysis, 17th edn. Association of official analytical chemists, Washington.

Considine, D. M and Considine, G. D. 1997. Processing and production of soy beans; Improvement, production and uses. IN: Caldwell BE. (Edn.), USA: American Society for Agronomy Inc.

Fekria, A. M., Elfadil, E. B., Isam, A. M. A and Suha, O. A. 2012. Nutritional and functional characterization of defatted seed cake flour of two Sudanese groundnut (Arachis hypogaea) Cultivars. International Food Research Journal. 19(2): 629-637.

Jain, P., Deep Narayan Yadav, Hradesh Rajput and Devendra Kumar Bhatt. 2013. Effect of pressure blanching on sensory and proximate composition of peanut milk. Journal of Food Science and Technology. 50(3): 605-608.

Madhusudhana, B. 2013. A survey on area, production and productivity of groundnut crop in India. IOSR Journal of Economics and Finance. 1(3): 01-07. www.iosrjournals.org

Mattes, R. D, Kris-Etherton P and Foster, G. D. 2008. Impact of peanuts and tree nuts on body weight and healthy weight loss in adults. Journal of Nutrition. 138: 1741-1745.

Saio K (1986) Interaction among traditional and emerging food processing technologies observed in Japanese food industries. In: Traditional foods - some products and technologies, central food technological research Institute Mysore, India, Pp. 209-216.

Salunkhe, D. K., and Kadam, S. S. (1989). Handbook of world food legumes: nutritional chemistry, processing technology, and utilization. Vol. 2, CRC Press. Inc., Boca Raton.

\section{How to cite this article:}

Perugu Balachandra Yadav, L. Edukondalu, S. Patel and Bhaskara Rao, D. 2018. Proximate Composition of Peanut Milk Prepared by Different Methods. Int.J.Curr.Microbiol.App.Sci. 7(10): 2388-2391. doi: https://doi.org/10.20546/ijcmas.2018.710.276 